\title{
TINJAUAN MAQASHID SYARIAH TERHADAP KONSUMSI
}

\author{
Annisa Masruri Zaimsyah \& Sri Herianingrum \\ Pascasarjana, Universitas Airlangga \\ E-mail: annisa.masruri.zaimsyah-2018@pasca.uair.ac.id
}

\begin{abstract}
The purpose of this paper to look at consumer ethics in the view of maqasid sharia, because of the high level of consumption of a Muslim who is not in accordance with Islamic principles. In consuming a Muslim must also look at the maslahah of the products consumed. Maqasid sharia is the basis for a Muslim to consume halal food. Maqosid sharia is very necessary to be described so as to provide an understanding of the rationale based on sharia for humanity to live according to Islamic law. In consuming consumer behavior, it must be based on what has been regulated by Islamic law, namely: consuming Halal and Service Goods which are permitted which are clearly halal and haram, consumption for life in the world and the hereafter, paying attention to expenditure patterns so that income and expenditure are balanced, unlimited human desires but consumption must be balanced, a standard of living that is simple and not extravagant, does not accumulate wealth, and considers halal and haram what is consumed. So that to meet primary, secondary and tertiary needs must be in accordance with Islamic principles.
\end{abstract}

Keyword: Ethics Consumtion, Maqashid Syariah, Convensional Economic

\section{Pendahuluan}

Dewasa ini, banyak cendikiawan Islam membahas mengenai nilai-nilai, etika dan moral yang harus ditekankan dalam transaksi sehari-hari. Singkatnya, etika konsumsi dalam Islam dapat dibagi menjadi tujuh bagian utama. Diantaranya mengacu pada kebutuhan, melestarikan dan menjaga maqasid syariah, mematuhi prinsip-prinsip halal dan haram, kualitas konsumsi, dan melihat maslahah individu dan masyarakat serta prakteknya pada zaman modern ini $^{1}$. Konsumsi merupakan suatu hal yang niscaya dalam kehidupan manusia, karena ia membutuhkan berbagai konsumsi untuk dapat mempertahankan hidupnya. Ia harus makan untuk hidup, berpakaian untuk melindungi tubuhnya dari berbagai iklim ekstrem, memiliki rumah untuk dapat berteduh, beristirahat sekeluarga, serta menjaga dari berbagai gangguan fatal. ${ }^{2}$

\footnotetext{
${ }^{1}$ Mustafar dan Joni Tamkin Borhan, Muslim Consumer Behavior: Emphasis on Ethics from Islamic Perspective. Middle-East Journal of Scientific Research, 1302.

${ }^{2}$ Idri, Hadis Ekonomi: Ekonomi dalam Prespektif Hadis Nabi, (Jakarta: Kencana, 2015), 133. 
Teori perilaku konsumsi yang berkembang saat ini adalah bagaimana seorang konsumen dapat memaksimalkan utility (kepuasan) dengan sejumlah pendapatan yang terbatas. Padahal tingkat utilitas manusia tidaklah terbatas. Akibatnya, mereka membelanjakan hartanya untuk hal-hal yang tidak bermanfaat (diluar kebutuhan) dan tidak sesuai dengan batasan-batasan yang ditetapkan oleh syariat. Bahkan mereka berlomba-lomba dalam hal kemewahan dan kemegahan sekedar untuk menyombongkan diri dan menjaga prestige. ${ }^{3}$ Dalam mengkonsumsi kita juga harus melihat kemanfaat objek yang dikonsumsi apakah ada kemanfaatannya bagi diri sendiri dan juga bagi orang lain.

Manusia sebagai khalifah di muka bumi memiliki tanggung jawab akan keharmonisan yang ada di alam. Penggunan segala sesuatu yang ada di muka bumi sudah ada proporsinya masing-masing dan kita sebagai khalifah hendaknya mengelola dengan baik apa yang telah disediakan oleh Allah untuk kemaslahatan umat manusia. Telah jelas dicontohkan dalam Al-Qur'an mengenai kaum yang melanggar perintah Allah yaitu kaum 'Ad dan Tsamud. Dimana kedua kaum tersebut diberikan kenikmatan yang luar bisaa namun mereka telah sombong tidak mau bersyukur kepada Allah maka Allah menurunkan adzab yang pedih kepada mereka. Sebagai mahluk sosial manusia pasti membutuhkan air, makanan, kehidupan social, tempat tinggal. Mereka harus menggunakan apa yang ada di bumi untuk memenuhi kebutuhan dasar. Dan hal ini dapat menimbulkan konflik baik dengan alam maupun sesama manusia.

Konsumsi yang Islami selalu berpedoman pada ajaran Islam. Di antara ajaran yang penting berkaitan dengan kmonsumsi, misalnya perlu memperhatikan orang lain. Selanjutnya juga, diharamkan bagi seorang muslim hidup dalam keadaan serba berkelebihan semetara ada tetangganya yang menderita kelaparan. Hal lain adalah tujuan konsumsi itu sendiri, di mana seorang Muslim akan lebih mempertimbangkan maslahah Islam (maqasid syariab), yang tentu saja harus menjadi tujuan dari kegiatan konsumsi. ${ }^{4}$

Konsumsi seorang muslim juga harus melihat kepada maslahah dari produk yang dikonsumsi. Maqasid syariah sebagai landasan seorang muslim untuk mengkonsumsi makanan halal. Maqasid syariah sangat diperlukan untuk digambarkan sehingga memberikan pemahaman tentang dasar pemikiran dari pedoman syariah bagi umat manusia untuk hidup ini sesuai dengan hidup yang Islami. ${ }^{5}$ Dalam peraturan pemerintah No 69 Tahun 1999 tentang pangan halal pasal 1 ayat 5, sudah dijelaskan bahwasanya pangan yang mengandung unsur

\footnotetext{
${ }^{3}$ Abdul Wahid, Ekonomi Islam: Analisis Mikro dan Makro, (Yogyakarta: Graha Ilmu, 2018), 260.

${ }^{4}$ P3EI, Ekonomi Islam, (Jakarta: Rajawali Pers, 2014), 128.

${ }^{5}$ Abdullah, Risk Management via Takaful from a Perspective of Maqasid of Shariah. Social and Behavioral Sciences, (tanpa tempat: tanpa penerbit, 2012), 538.
} 
haram atau bahan yang haram dilarang untuk dikonsumsi umat Islam. Sehingga dalam tulisan ini akan meninjau bagaimana Etika Konsumsi dalam prespektif Maqashid Syariah.

\section{Orientasi Etika Konsumsi dalam Ekonomi Konvensional dan Ekonomi Islam}

Kepuasan dan ketidakpuasan pelanggan dipengaruhi oleh harapan sebelumnya bahwa konsumen sudah memikirkan tingkat kualitas. Konsumen membentuk keyakinan tentang kinerja produk berdasarkan pengalaman sebelumnya dengan produk dan / atau komunikasi tentang produk yang menyiratkan tingkat kualitas tertentu ${ }^{6}$.

Dalam ekonomi konvensional, konsumen diasumsikan mempunyai tujuan untuk memperoleh (utility) dalam kegiatan konsumsinya. Untility secara bahasa berarti berguna (usefulness), membantu (belpfulness), atau menguntungkan (advantage). Dalam konteks ekonomi utilitas dimaknai sebagai kegunaan barang yang dirasakan oleh seorang konsumen ketika mengkonsumsi suatu barang. Kegunaan ini bisa juga dirasakan sebagai rasa "tertolong" dari suatu kesulitan karena mengkonsumsi barang tersebut. Dikarenakan ada rasa inilah, maka sering kali utilitas dimaknai rasa puas atau kepuasan yang dirasakan oleh seseorang konsumen dalam mengkonsumsi suatu barang. Jadi, kepuasan dan utilitas merupakan akibat yang ditimbulkan oleh utilitas. ${ }^{7}$ Dalam Islam, tujuan konsumsi bukanlah konsep utilitas melaikan kemaslahatan (maslahah). Pencapaian maslahah tersebut merupakan tujuan dari maqashid syari'ah.

Prilaku konsumen dalam teori ekonomi konvensional (kapitalis), beberapa prinsip dasar dalam analisis perilaku konsumen adalah: ${ }^{8}$ (a) Kelangkaan dan terbatasnya pendapatan. Adanya kelangkaan dan terbatasnya pendapatan memaksa orang menentukan pilihan, agar pengeluaran tetap berada pada anggaran yang telah ditetapkan. (b) Konsumen mampu membandingkan biaya dengan manfaat. Jika dua barang memberi manfaat yang sama, konsumen akan memilih yang biayanya lebih kecil, bila untuk memperoleh dua jenis barang dibutuhkan biaya yang sama, maka konsumen akan memilih barang yang memberi manfaat lebih besar. (c) Tidak semua konsumen dapat memperkirakan manfaat dengan tepat. Saat membeli barang, bisa jadi manfaat yang diperoleh tidak sesuai dengan harga yang harus dibayarkan. (d) Setiap barang dapat disubstitusi dengan barang lain. Dengan demikian konsumen dapat memperoleh kepuasan dengan berbagai cara. (e) Konsumen tunduk kepada

\footnotetext{
${ }^{6}$ Nor Marini Mohatar, Ayamas Food Corporation Sdn, Journal Social and Behavioral Sciencesi, (tanpa tempat: tanpa penerbit, 2014), 170.

7 P3EI, Ekonomi Islam ....127.

${ }^{8}$ Mustafar dan Joni Tamkin Borhan, Muslim Consumer Behavior: Emphasis on Ethics from Islamic Perspective....1304.
} 
hukum berkurangnya tambahan kepuasan (The Law of Diminishing Marginal Utility). Semakin banyak jumlah barang dikonsumsi, semakin kecil tambahan kepuasan yang dihasilkan

Teori perilaku konsumen dalam pandangan ekonomi konvensional didasari pada prinsip-prinsip dasar utility dan memberikan kepuasan dalam kegiatan konsumsinya. Utility yang dimaksud adalah kemampuan konsumen untuk memberikan kepuasan total terhadap dirinya sendiri. Dalam ilmu ekonomi konvensional, menurut Sulistyo disebutkan, bahwa perilaku konsumsi seseorang dipengaruhi oleh faktor internal di dalam diri manusia dan faktor eksternal dari luar diri manusia. Orang meminta barang dan jasa karena barang dan jasa dapat memenuhi kebutuhan hidupnya yang bersifat material. Tetapi di lain pihak perilaku konsumsi seseorang dapat diimbas dari luar yaitu melalui iklan-iklan yang gencar dipasang di berbagai media, hal ini dapat memengaruhi keputusan seseorang pada era modern untuk berkonsumsi. Banyak orang membeli barang dan jasa hanya karena tertarik oleh iklan dan sama sekali tidak ada kaitan dengan usaha pemenuhan kebutuhan hidupnya. Sebagaimana yang dikutip oleh Andi Bahri, Keynes pun mengemukakan bahwa perilaku konsumsi didorong motif yang berasal dari dalam diri manusia itu sendiri yang bersifat subyektif, yaitu keinginan untuk memenuhi kebutuhan hidupnya.

Ada beberapa prinsip dalam berkonsumsi bagi setiap muslim yang membedakannya dengan perilaku konsumsi nonmuslim (konvensional). Prinsip tersebut didasarkan dari ayat-ayat Al-Qur'an dan Hadist Nabi SAW dan perilaku sahabat r.a. prinsip-prinsip tersebut antara lain:?

1. Prinsip Syariah

a. Memperhatikan Tujuan Konsumsi

Perilaku konsumsi muslim dari segi tujuan tidak hanya mencapai kepuasan dari konsumsi barang, melaikan berfungsi "ibadah" dalam rangka mendapat ridha Allah SWT sebagaimana firman Allah SWT dalam surat AL An'am ayat 162:

"katakanlah: Sesunggubnya shalatku, ibadahku, bidupku, dan matiku hanyalah untuk. Allab, Tuban Semesta Alam".

Kata "hidupku" maknanya termasuk di dalamnya konsumsi. Perilaku konsumsi muslim berfungsi sebagai ibdah sehingga merupakan amal soleh, karena setiap perbuatan perintah dari Allah mengandung Ibadah. Demikian juga berkonsumsi merupakan sunnah Nabi Muhammad SAW, dimana Nabi mencontohkan tata cara makan. Apalagi ketika melaksanakan perintah makan atau berkonsumsi dalam arti luas, maka pelaksanaannya mencontoh Nabi Muhammad SAW, baik secara kualitas maupun kuantitas

\footnotetext{
${ }^{9}$ Lukman Hakim, Prinsip-prinsip Ekonomi Islam, (Surakarta: Erlangga, 2012), 93-100.
} 
b. Memperhatikan Kaidah Ilmiah

Dalam berkonsumsi, seorang muslim harus memperhatikan prinsip kebersihan. Prinsip kebersiban mengandung arti barang yang dikonsumsi harus bebas dari kotoron ataupun penyakit, demikian pula harus menyehatkan, bernilai gizi dan memiliki manfaat bukan kemudhoratan.

c. Memperhatikan bentuk konsumsi

Dari segi bentuk konsumsi, seorang muslim harus memperhatikan apapun yang dikonsumsinya. Hal ini tentu berhubungan dengan adanya batasan orang muslim dalam mengkonsumsi suatu barang dan jasa. Seorang muslim dilarang mengkonsumsi daging babi, bangkai, darah, minuman keras, candu/narkotik, dan berjudi. Berbeda dengan bentuk konsumsi konvensional yang tidak mengenal batasan. Berapa pun yang dikonsumsi selagi anggaran terjangkau tidak menjadi masalah. Dari segi jenis pemuas konsumsi pun tidak ada batasannya, apakah sesuai dengan agama atau tidak, yang penting memuaskan nafsu konsumsinya maka terjadilah konsumsi yang sah.

2. Prinsip Kuantitas

a. Sederhana, tidak bermewah-mewah

Dalam berkonsumsi hendaknya sederhana dan tidak bermewah-mewah. Sikap bermewah-mewah merupakan perilaku konsumsi yang jauh dari nilai-nilai syariah, bahkan merupakan indicator terhadap kerusakan dan goncangannya terhadap hidup masyarakat.

b. Kesesuaian antara pemasukan dengan Konsumsi

Kesesuaian antara pemasukan dan konsumsi adalah hal yang sesuai dengan fitrah manusia dan realita. Karena itu, salah satu aksiomatik ekonomi adalah bahwa pemasukan merupakan salah satu factor yang mempengaruhi permintaan konsumen individu. Dimana permintaan menjadi bertambah jika pemasukan bertambah, dan permintaan menjadi berkurang jika pemasukan menurun disertai tetapnya factor-faktor yang lain.

3. Prinsip Prioritas

Prinsip prioritas dalam mengkonsumsi maksudnya, konsumen muslim harus memprioritaskan kebutuhan pokok terlebihdahulu atau prioritas yang ditanggung. Selain itu prioritas yang kedua adalah untuk memperjuangkan agama Allah. Pengeluaran dijalan Allah dapat berbentuk pengeluaran untuk membiayai dakwah agama agar Islam tersebar ke seluruh alam.

4. Prinsip Moralitas

Perilaku konsumsi seorang muslim dalam berkonsumsi juga memperhatikan nilai moralitas, dimana mengandung arti ketika berkonsumsi terhadap suatu barang, maka dalam rangka menjaga martabat manusia yang mulia, berbeda 
dengan mahluk Allah lainnya. Sehingga dalam berkonsumssi harus menjaga adab dan etika yang disunnahkan Nabi Muhammad SAW.

Menurut M. Abdul Manna, perintah Islam mengenai konsumsi dikendalikan oleh lima prinsip, yaitu:

1. Prinsip Keadilan

Islam mendefinisikan adil adalah tidak mendzalimi dan tidak dizalimi. ${ }^{10}$ Prinsip keadilan mengandung unsur dalam berkonsumsi tidak boleh mendzalimi orang lain atau mendzalimi diri sendiri.

2. Prinsip Kebersihan

Prinsip kebersihan mengandung arti luas dan sempit dalam konsumsi, arti luas yaitu sesuatu yang dikonsumsi harus bersih dan sesuai dengan ketentuan syariat. Sedangkan dalam arti luas yaitu barang yang dikonsumsi harus bersih dan sehat artinya terhindar dari penyakit.

3. Prinsip Kesederhanaan

Al-Qur'an menyebut kaum Muslimin sebagai umat pertengahan, dank arena itu Islam menganjurkan prinsip kesederhanaan dan keseimabangan dalam semua langkah. Di dalam bidang konsumsi, harta maupun makanan, sikap pertengahan adalah sikap utama. Baik "kurang dari semestinya: (yakni kikir) maupun lebih dari semestinya (berlebihan) dilarang $^{11}$.

a. Kikir. Orang yang kikir adalah orang yang tidak membelanjakan uang untuk dirinya maupun keluarganya sesuai degan kemampuannya, demikian pula ia tidak mengelurakan uangnya untuk sedekah.

b. Boros. Islam mengutuk pemborosan seperti halnya kekikiran, karena keduanya berbahaya bagi perekonomian Islam. Kekikiran menahan sumber daya masyarakat sehingga tidak dapat digunakan dengan sempurna, sementara pemborosan menghamburkan sumber daya itu untuk hal-hal yang tak berguna dan berlebihan.

c. Sederhana. Sikap tengah antara dua ekstrim kikir dan boros direkomendasikan oleh Islam sebagai jalan yang terbaik.

4. Prinsip Kemurahan Hati

Dalam berkonsumsi juga harus menerapkan prinsip mutah hati, dimana seorang konsumen harus iklas dan tanpa ada paksaan, selain itu konsumen juga harus mengeluarkan sedekah sebagai aspek sosial.

5. Prinsip Moralitas.

${ }_{10}$ Akhmad Mujahidin, Ekonomi Islam Sejarah, Konsep, Instrumen, Negara dan Pasar. (Jakarta: PT RajaGrafindo Persada, 2014), 21.

${ }_{11}$ Muhammad Sharif Chaudhry, Sistem Ekonomi Islam: Prinsip DasaR, (Jakarta: Kencana, 2012), 146. 
Prinsip moralitas mengandung arti bahwa perilaku kinsumen harus tunduk kepada norma-norma Islam yang berlaku. Kelima prinsip ini menjadi pegangan dalam aktivitas konsumsi yang sejalan dengan ajaran Islam. Adapun menurut Yusuf Qardawi, prinsip-prinsip konsumsi dalam ekonomi Islam adalah:12 Menjauhi sifat kikir dan mendayagunakan harta dalam kebaikan, memerangi kemuaziran dalam berkonsumsi, dan bersikap sederhana dalam konsumsi.

Dari bebera referensi yang penulishimpun, maka dapat disimpulkan bahwa etika konsumsi Islam sebagai berikut:

1. Taubid, dalam mengkonsumsi, sifat tauhid merupakan landasan utama seorang muslim mengkonsumsi, dalam hal ini, seorang Muslim harus benar-benar menerapkannya. Seorang Muslim percaya bahwasanya segala sesuat yang ada tidak diciptkan sia-sia, akan tetapi setiap yang diciptakan ada tujuannya. Tujuan diciptakan manusia adalah untuk beribadah kepada Allah. Karena segala aktivitas manusia dalam hubungannya dengan alam dan sumber daya manusia berhubungan dengan Allah, selain itu, Allah menciptakan manusia juga sebagai khalifah di muka bumi untuk menjaga bumi dari kerusakan. Seperti yang dijelaskan dalam Al-Qur'an surat Ala'raf ayat 56-58:

(56) "Dan janganlah kamu membuat kerusakan di muka bumi, sesudah (Allah) memperbaikinya dan berdoalah kepada-Nya dengan rasa takut (tidak akan diterima) dan harapan (akan dikabulkan). Sesunggubnya rahmat Allah amat dekat kepada orang-orang yang berbuat baik (57) Dan Dialah yang meniupkan angin sebagai pembawa berita gembira sebelum kedatangan rahmat-Nya (bujan); bingga apabila angin itu telah membawa awan mendung, Kami halau ke suatu daerah yang tandus, lalu Kami turunkan bujan di daerah itu, maka Kami keluarkan dengan sebab bujan itu pelbagai macam buah-buahan. Seperti itulah Kami membangkitkan orang-orang yang telah mati, mudah-mudahan kamu mengambil pelajaran (58) Dan tanah yang baik, tanaman-tanamannya tumbuh subur dengan seizin Allab; dan tanah yang tidak, subur, tanaman-tanamannya hanya tumbub merana. Demikianlah Kami mengulangi tanda-tanda kebesaran (Kami) bagi orang-orang yang bersyukur" (QS. Al-A'raf: 56-58)

Dari ayat al-A'raf ini sudah dijelaskan bahwasanya Allah melarang manusia untuk berbuat kerusakan dimuka bumi, sehingga tugas manusia menjaga dan melestarikan lingkungan. Allah juga telah menurunkan rahmat dan karunia-Nya kepada manusia untuk tetap menjaga dan melestarikan lingkungan. Sehingga sifat tauhid ini sangat perlu diterapkan agar manusia dalam mengkonsumsi tidak merusak lingkungan.

${ }^{12}$ Idri, Hadis Ekonomi: Ekonomi dalam Prespektif Hadis Nabi...113. 
2. Keseimbangan. Islam mengharamkan sikap boros, kikir dan menghamburkan harta. Inilah bentuk keseimabangan yang diperintahkan dalam Al-Qur'an yang mencerminkan sikap keadilan dalam konsumsi. Seperti yang telah dijelaskan dalam surat Al-Isra' ayat: 29: ${ }^{13}$

(29) "Dan janganlah kamu jadikan tanganmu terbelenggu pada lehermu dan janganlah kamu terlalu mengulurkannya karena itu kamu menjadi tercela dan menyesal" (QS. Al-Isra': 29)

Dalam surat Al-Isra' ayat 26: 'Dan berikanlah kepada keluarga-keluarga yang dekat akan haknya, kepada orang miskin dan oran $\mathrm{Rg}$ yang dalam perjalanan dan janganlah kamu menghambur-hamburkan (bartamu) secara boros." (QS. Al-Isra': 26)

Dari ayat Al-Qur'an ini dijelaskan bahwa manusia dilarang melakukan pemborosan, karena pemborosan dan menghamburhamburkan harta perbuatan tercela. Inilah yang dikatakan seimbang dalam konsumsi.

3. Tanggung Jawab. Tanggung jawab dalam mengkonsumsi ini dimaksudkan adalah tanggung jawab manusia sebagai khalifah, tanggung jawab ini terkait tanggung jawab manusia sebagai khalifah terhadap untuk mengelola sumber daya alam di dunia ini, juga berkaitan dengan menjaga lingkungan hidup. Manusia harus bertanggung jawab dengan apa yang telah diperbuatnya, sehingga dalam mengkonsumsi produk plastik seorang muslim harus bertanggung jawab menjaga kelestarian lingkungan hidup seperti mendaur ulang produk plastik tersebut.

4. Kehendak Bebas (Free Will). Kebebasan maksudnya bebas melakukan kehendak manusia, akan tetapi kebebasab ini bukan semata-mata bebas melakukan sesuka hati manusia, akan tetapi berkehendak dengan mengikuti aturan dan syariat Islam. Mengkonsumsi secara bebas dengan tidak menciptakan kumdhoratan dilingkungan dan orang lain.

5. Larangan Bersikap Royal dan Sia-sia. Islam melarang manusia untuk bersikap Israf (royal) dan sia-sia, sehaingga Islam melarang gaya hidup mewah yang dapat merusak individu dan masyarakat karena menyibukkan manusia dengan hawa nafsu, melaikan dari hal-hal yang mulia dan akhlak yang luhur. Seperti yang telah dijelaskan dalam QS. Al A'raf: 31: "Hai anak. Adam, pakailah pakaianmu yang indah di setiap (memasuki) mesjid, makan dan minumlah, dan janganlah berlebih-lebihan. Sesunggubnya Allab tidak menyukai orang-orang yang berlebih-lebihan.” (QS. Al-A'raf: 31)

${ }_{13}$ Rozalinda, Ekonomi Islam: Teori dan Aplikasinya pada Aktivitas Ekonomi,( Jakarta: Rajawali Pres, 2015), 108. 
Sehingga jelas perbedaan orientasi dari konsumsi Islam dan Konvensional. Jika konsumsi dalam konvensional lebih mengutamakan Utility sedangkan dalam Islam lebih mengutamakan Maslahah.

\section{Konsumsi dalam Pandangan Maqashid Syariah}

Menurut Imam al-Ghazali tujuan syariah adalah untuk mempromosikan kesejahteraan umat manusia, yang terletak dalam menjaga iman (din), diri manusia (nafs), kecerdasan ('aq), keturunan (nas), dan kekayaan (mal) $)^{14}$ Substansi maqasid syariah adalah kemaslahatan. Kemaslahatan dalam taklif Tuhan dapat berwujud dua bentuk, yaitu: pertama, dalam bentuk hakiki, yakni manfaat langsung dalam arti kausitas, kedua, dalam bentuk majazi, yakni bentuk yang membawa kemashlahatan. Makna maslahah adalah 'kepentingan umum'. Maslahah kadang-kadang mengandung makna yang sama dengan maqasid, dan para ahli telah menggunakan kedua istilah ini hampir secara bergantian. Teori Maqasid syariah dalam wilayah ekonomi Islam dapat ditemukan secara langsung dalam landasan etika. Para pelaku ekonomi tidak hanya dituntut untuk dapat menguasai sumber-sumber ekonomi yang strategis tetapi juga memanfaatkannya untuk kepentingan umat dengan mengacu pada kemaslahatan dharuriyah, hajiyyah, dan tabsiniyyah.

\section{a. Dharuriyah (Primer)}

Kebutuhan dharuriyah atau primer ialah kemaslahatan yang menjadi dasar tegaknya kehidupan asasi manusia baik yang berkaitan dengan agama maupun dunia. Jika dia luput dari kehidupan asasi manusia maka mengakibatkan rusaknya tatanan kehidupan manusia tersebut. Maslabah dharuriyah ini merupakan dasar asasi untuk terjaminnya kelangsungan hidup manusia. Jika manusia rusak maka akan muncul fitnah dan ancaman besar. Dalam memnuhi kebutuhan primer yang paling utama yang harus diperhatikan adalah kemaslahatan, akan tetapi apabila dalam keadaan darurat yang mengancam nyawa diperbolehkan memakan makanan yang haram, tapi hanya pada keadaan darurat saja. Apabila tidak dalam keadaan darurat yang mengacam nyawa seseorang memakan makanan haram dilarang dalam Islam.

Pemenuhan kebutuhan primer tetap harus dalam kapasitas yang seimbang (altawazun), tidak boleh berlebih-lebihan (al-israf), dan juga bakhil (al-bukbh). Dalam Islam, konsumsi tidak dapat dipisahkan dari peranan keimanan. Peranan keimanan menjadi tolak ukur penting karena keimanan membicarakan pandangan dunia yang cenderung mempengaruhi kepribadian manusia. Keimanan sangat mempengaruhi kuantitas dan kualitas konsumsi baik dalam bentuk kepuasan material maupun spiritual

14 Asyraf Wajdi Dusuki, Maqasid al-Shari ah, Maslahah, and Corporate Social Responsibility, The American Journal of Islamic Social Sciences, (tanpa tempat: tanpa penerbit, 2007), 30. 
Dalam rangka mewujudkan kemaslahatan di dunia dan di akhirat berdasarkan penelitian para ahli ushul Figh, ada lima unsur pokok yaitu agama, jiwa, akal, keturunan serta harta. Penerepan kelima unsur ini berfungsi sebagai Al-Qawaid kulliyat yang berhubungan dengan solat, larangan mengkonsumsi yang memabukkan, larangan melakukan transaksi bisnis terlarang.

Lima maslahah dasar tersebut dapat dijelaskan (a) memelihara agama, maksutnya tidak menyekutukan Allah dalam segala hal, baik itu dalam kegiatan ekonomi terutama dalam konsumsi, dengan menjaga makanan yang dikonsumsi membuktikan bahwa seorang muslim juga menjaga agamanya. (b) memelihara jiwa, menjaga jiwa dengan pemeliharaan yang tidak terbatas, memlihra untuk kemaslahatan jiwa, sehingga seorang muslim dengan mengkonsumsi makanan yang halal dan baik akan menjaga jiwanya. (c) memelihara akal, dalam mengkosumsi manusia juga harus memelihara akal, karena akal adalah nikmat Allah yang tak terhingga, hanya manusia yang diberikan akal, apabila manusia tidak menggunakan akalnya maka akan sama saja derajat manusia dengan hewan, begitu pula dengan mengkonsumsi manusia harus menggunakan akal sehatnya. (d) menjaga keturunan, keturunan merupakan harta yang pokok dalam kehidupan, sehingga dengan perilaku konsumen yang sesuai syariat Islam manusia akan ikut serta dalam menjaga keturunannya. (e) memelihara harta, harta merupakan kemaslahatan dunia, sehingga dalam mencari kebutuhan hidup haruslah harta yang halal.

Dari kelima maslahah ini, sudah jelas bahwasanya konsumen muslim harus berhati-hati dalam mengkonsumsi, baik itu, makanan, pakaian atau yang lainnya, konsumen muslim harus memperhatikan kemaslahatan dari apa yang dikonsumsinya, melihat halal atau haram sesuatu yang di konsumsi. Konsumen harus mengkonsumsi makanan halal (halal food), dengan memperhatikan sertifikat halal yang ada pada produk tersebut. Akan tetapi, dalam Islam juga melarang mengkonsumsi makanan secara berlebihan karena banyak mudharat akibat makan yang berlebihan, baik itu dari penyakit rohani maupun jasmani.

b.Hajiziah (Sekunder)

Kebutuhan bajizat adalah kebutuhan sekunder atau kebutuhan setelah kebutuhan dharuriyat. Apabila kebutuhan hajizat tidak terpenuhi tidak akan mengancam keselamatan kehidupan umat manusia, namun manusia tersebut akan mengalami kesulitan dalam melakukan suatu kegiatan. Kebutuhan ini untuk menghilangkan kesulitan, kesusahan, kesempitan dan ibtiyath (berhatihati).

c. Tabsiniyat (tersier)

Kebutuhan tabsiniyat (tersier) atau kamaliyat (pelengkap) adalah tingkat kebutuhan yang apabila tidak terpenuhi tidak mengancam eksistensi salah satu dari kelima pokok diatas serta tidak pula menimbulkan kesulitan untuk 
manusia. Maslahah dalam jenis ini ialah sifatnya untuk memelihara kebagusan dan kebaikan budi pekerti serta keindahan saja. Sekiranya kemaslahatan tidak dapat diwujudkan dalam kehidupan tidaklah menimbulkan kesulitan dan kegoncangan serta rusaknya tatanan kehidupan manusia.

\section{Kesimpulan}

Seorang muslim harus memperhatikan Etika konsumsinya sebagai berikut: (1) Seorang Muslim yang mengkonsumsi makanan haruslah melihat baik atau tidaknya makanan yang dikonsumsinya baik untuk dunia maupun untuk akhirat, serta selalu memperhatikan halal dan haramnya makanan tersebut, (2) Mengkonsumsi makanan sebaiknya seadanya saja tidak berlebihan (Israf), (3) Islam melarang untuk menimbun harta, begitu juga dalam berkonsumsi, seorang muslim dilarang dalam menimbun hartanya, (4) Tidak membuang-buang makanan atau mubazir, Karena kemubaziran adalah perbuatan yang tercela. (5) Konsumsi sebagai penunjang kehidupan untuk masa yang akan datang.

Substansi maqasid syariah terhadap perilaku konsumsi adalah kemaslahatan. Kemaslahatan dalam taklif Tuhan dapat berwujud dua bentuk, yaitu: pertama, dalam bentuk hakiki, yakni manfaat langsung dalam arti kausitas, kedua, dalam bentuk majazi, yakni bentuk yang membawa kemashlahatan. Makna maslahah adalah "kepentingan umum". Maslahah kadang-kadang mengandung makna yang sama dengan maqasid, dan para ahli telah menggunakan kedua istilah ini hampir secara bergantian. Dalam pandangan Maqasid Syariah konsumsi harus melihat lima maslahah dasar yaitu: memelihara agama, memelihara jiwa, memelihara akal, memelihara keturunan dan memelihara harta.

\section{Daftar Pustaka}

Abdullah, S. (2012). Risk Management via Takaful from a Perspective of Maqasid of Shariah. Social and Behavioral Sciences, 535-541.

Asyraf Wajdi Dusuki , N. (2007). Maqasid al-Shari`ah, Maslahah, and Corporate Social Responsibility. The American Journal of Islamic Social Sciences , 2545.

Aziz, Abdul. (2008). Ekonomi Islam: Analisis Mikro dan Makro. Yogyakarta: Graha Ilmu.

Chaudhry, Muhammad Sharif. (2012). Sistem Ekonomi Islam: Prinsip Dasar. Jakarta: Kencana

Hakim, Lukman (2012), Prinsip-prinsip Ekonomi Islam. Surakarta: Erlangga. 
Idri. (2015) Hadis Ekonomi: Ekonomi dalam Prespektif Hadis Nabi. Jakarta: Kencana.

Mujahidin, Akhmad (2014). Ekonomi Islam Sejarah, Konsep, Instrumen, Negara dan Pasar. Jakarta: PT RajaGrafindo Persada.

Mustafar, M. Z., \& Joni Tamkin Borhan. (2013). Muslim Consumer Behavior: Emphasis on Ethics from Islamic Perspective. Middle-East Journal of Scientific Research, 1301-1307.

Nor Marini Mohtar, N. D. ( 2014 ). Ayamas Food Corporation Sdn. Procedia - Social and Behavioral Sciences 121, 166 - 185.

P3EI, Pusat Pengkaji dan Pengembangan Ekonomi Islam (2014). Ekonomi Islam. Jakarta: Rajawali Pers.

Rozalinda (2015). Ekonomi Islam: Teori dan Aplikasinya pada Aktivitas Ekonomi. Jakarta: Rajawali Pres

Yunia., Abdul Kadir R, (2014), Prinsip Dasar Ekonomi Islam Prespektif Maqashid Syariah. Jakarta: Kencana. 